\title{
El ejercicio de la Beneficencia. Espacio de prestigio y herramienta de control social en el centro y sur bonaerense a fines del siglo $\mathrm{XIX}^{*}$
}

\author{
Yolanda de Paz Trueba ${ }^{* *}$
}

\begin{abstract}
Resumen:
En la Argentina de fines del siglo XIX se hacía indispensable para el Estado (que se sentía amenazado por el desorden social) consolidarse, instalando un modelo de sociedad y de familia. El objetivo del presente trabajo es analizar las formas concretas en que las instituciones de beneficencia se erigieron en agentes moralizadores en algunas localidades del centro y sur bonaerense a fines del siglo XIX, así como los límites que los controles que se pretendía instalar por su intermedio encontraron en la práctica. En estas instituciones las mujeres pertenecientes a los sectores notables fueron transmisoras de valores y agentes de control sobre los sectores populares de la sociedad, al mismo tiempo que encontraron un canal para ejercer la ciudadanía a pesar de ser actores sociales a quienes sólo se les consideraba sujetos de derecho en tanto madres de ciudadanos.
\end{abstract}

Palabras Claves: Beneficencia, Mujeres, Ciudadanía

En la Argentina de fines del siglo XIX y principios del XX, la frustración de las esperanzas que habían sido depositadas en el aporte de la inmigración con relación a la población del territorio, así como los problemas que ésta trajo aparejados, pusieron de manifiesto las necesidades de intervención pública en el ámbito privado de las familias y su reproducción. La medicina moderna cumplió en este sentido un papel central, colaborando con las pautas y necesidades políticas del momento, al naturalizar la maternidad, el amor de madre y el instinto maternal. Se pretendía así imponer, biologizándolo, el ideal de que la misión de la mujer en la sociedad era el de ser madre y dar ciudadanos a la joven nación, en un marco de conflictividad social que se acentuaba ${ }^{1}$. Como sostiene Marcela Nari, “... el estado politiza a la maternidad al convertirla en un objeto de preocupación y debate público y político.”² Existía una sensación de peligro social con fuertes implicancias políticas. Todo lo que se apartara del ideal de familia patriarcal y sexualmente jerarquizada que se quería imponer, era percibido como una amenaza para el orden social, y por cierto que los inmigrantes y las clases populares desarrollaron formas familiares que parecían ser la muestra más 
evidente de esos peligros y justificaban las intervenciones políticas en el seno familiar. ${ }^{3}$ Como plantea Nari, "Desde el siglo XIX podemos encontrar una fuerte tradición entre las elites letradas: la lectura de los desórdenes familiares de las clases populares como indicios y/ o gérmenes de desórdenes mas amplios, sociales y morales.”4

Las diferentes instancias del poder debieron atender a las demandas crecientes que llegaban desde diferentes sectores de la sociedad. En este sentido, cabe tener en cuenta la resignificación que adquirieron las instituciones caritativas, medio para dar una respuesta que, como plantea Marta Bonaudo, sin ser estatal, tenía un fuerte tinte político. ${ }^{5}$ En un marco donde el control social se hacía indispensable para un Estado que debía consolidarse y se sentía amenazado por el desorden social real o potencial, era imperioso imponer un modelo de sociedad y de familia y la madre virtuosa fue llamada al centro de la escena. La beneficencia representó para el poder local en nuestros espacios de estudio, como lo fue a nivel nacional, un medio para imponer controles en los sectores subalternos de la sociedad y para erradicar el molesto espectáculo de la pobreza.

El objetivo del presente trabajo es analizar las formas concretas en que estas instituciones se erigieron en agentes moralizadores y transmisores de los valores dominantes en algunas localidades del centro y sur bonaerense a fines del siglo XIX, así como los límites que los controles que se pretendía instalar por su intermedio encontraron en la práctica.

Prestaremos especial atención a la acción de las mujeres que se desempeñaron como agentes de un control que también estaba dirigido a ellas en tanto mujeres. Nos interesa poner de manifiesto cómo en estas instituciones las mujeres pertenecientes a los sectores notables representaron un papel de gran importancia como transmisoras de esos valores, y agentes de control sobre los sectores populares de la sociedad, ${ }^{6}$ al mismo tiempo que encontraron un canal para trascender la estrechez del espacio doméstico, haciéndose presentes en la esfera pública, desempeñando funciones que no iban en contra de lo socialmente aceptado. Nadie mejor que ellas para ocuparse de los necesitados, puesto que cumplían con el mandato que la naturaleza les demandaba y la sociedad reclamaba. Ocuparon así un espacio de poder que las autoridades locales no estaban aún preparadas para tomar y que justificaba su presencia pública, rompiendo con los preceptos que las condenaban a permanecer en el hogar. En síntesis, en su accionar observamos otros medios de ejercer la ciudadanía por parte de actores sociales a quienes sólo se les consideraba sujetos de derecho en tanto madres de ciudadanos. 
Estas y otras mujeres supieron encontrar espacios de participación alternativos sin ir en contra del lugar que la sociedad y las leyes les asignaban.

Finalmente, consideramos que el análisis de esta realidad en espacios geográficos hasta ahora inexplorados en este sentido, en la que el mapa social se vio transformado como en Bs. As. por la inmigración, pero estuvo a su vez afectado por contingencias propias, como la amenaza del ataque indígena o las distancias con relación a los centros poblados de mayor importancia entre otras, nos permite asomarnos a las formas de vida y los valores que esa sociedad consideraba centrales en la práctica, y ponía de manifiesto en su cotidianeidad, a caballo entre los valores y las costumbres, entre la prescripción y la libre acción.

\section{La beneficencia: actores y acciones}

La contraparte de las múltiples formas familiares y de vida, era la gran cantidad de niños librados a su suerte y que deambulaban por las calles. ${ }^{7}$

Hasta la creación del estado benefactor, entrado el siglo XX, la beneficencia no había sido una prerrogativa que quedara en manos del Estado, sino que eran prácticas detentadas por las órdenes religiosas o los particulares. Tal como señala José Luis Moreno, la creación de la Casa de Niños Expósitos en época colonial y la Sociedad de Beneficencia en 1823 durante el gobierno de Rivadavia pueden considerarse los dos antecedentes más significativos de la presencia del Estado en cuestiones caritativas. ${ }^{8}$ Sin embargo, el Estado no incorporó a la beneficencia dentro de su aparato burocrático, sino que en algunos casos fue su colaborador. Las asociaciones civiles, mutuales y religiosas, vinieron a cubrir estos vacíos. ${ }^{9}$

Además de las instituciones de beneficencia, existía a nivel municipal la figura del Defensor de Menores, personaje encargado de velar por la niñez desamparada y ubicarlos en lugares donde pudieran crecer con lo que se consideraban las garantías necesarias de formación moral. ${ }^{10}$ De acuerdo con Donna Guy, el sentido de peligrosidad que adquirieron los niños y niñas de la calle llevó a que fueran enviados a la cárcel, junto con delincuentes comunes, aunque su único delito, en la mayoría de los casos era ser pobres y no tener una familia que quisiera hacerse cargo de ellos. Cuando la cárcel no era la solución, el Defensor los “colocaba” con alguna familia que se encargaba de su guarda. ${ }^{11}$ En todos estos casos, fueran huérfanos o no, el Estado 
asumía la patria potestad porque se consideraba que sus padres no estaban en condiciones de ejercerla.

Como planteamos, el problema de la niñez abandonada no era menor, y la preocupación alrededor de este tema estaba ya presente en la etapa colonial. En el contexto de fin de siglo, estas cuestiones se reactualizaron, poniendo de manifiesto los peligros que podían representar algunos sectores, en especial los niños, considerados delincuentes y agitadores sociales en potencia. A abonar estas creencias, colaboraban no sólo el análisis de la realidad social que hacían políticos e intelectuales, sino también las corrientes científicas como el positivismo, la criminología lombrosiana y hasta la medicina moderna. La idea de peligro social acompañada del convencimiento de la necesidad de prevención de males futuros apuntando especialmente a los niños, centró su atención en aquellos más desprotegidos, los huérfanos o los que pasaban largas horas en las calles, trabajando o simplemente escapando por algunas horas del hacinamiento del conventillo. Como plantea Favio González, “... los niños de la calle se encontraban envueltos en el doble juego del peligro y la peligrosidad”. ${ }^{12}$

El problema de la niñez se entronca con la construcción del estereotipo femenino encauzado hacia la maternidad. En torno a la niñez existían ciertas construcciones sociales que eran, según Ríos y Talak, especies de moldes dentro de los que debía desarrollarse la vida de los niños. La familia y la escuela formaban un primer circuito. La familia bien constituida y en su interior el papel de la madre era fundamental, ya que tenía la función de moralizar la vida de los pequeños. Pero en el lado opuesto estaba el circuito de la calle, lugar identificado con el abandono, el vagabundaje, la prostitución, etc. y alrededor del cual también se articularon una serie de discursos. ${ }^{13}$

Pero, más allá de la discursiva, nos interesa preguntarnos por la práctica. ¿Qué sucedía en los hechos?, ¿cómo actuaba el Estado o sus representantes con los niños abandonados o huérfanos? Si en principio pensar que la entrada a un orfanato era un destino poco prometedor para un niño o niña, no todo parece indicar que haya sido así. De acuerdo con Donna Guy, el destino de muchos menores era la reclusión en cárceles junto a delincuentes comunes, al no existir un aparato a fines del sigo XIX preparado para hacer frente a las necesidades de dar amparo a los niños que lo necesitaban. Las vacantes en los asilos de huérfanos de la Sociedad de Beneficencia de Bs. As. eran reducidas y frente a la imposibilidad de colocar allí a la mayoría de los menores, los Defensores de Menores los depositaban en la cárcel o en casa de familias particulares. 
Si en realidad se suponía que allí debían ser educados y provistos de lo necesario para vivir, las más de las veces eran mano de obra barata y en muchos casos muy mal tratados, tal como lo plantea Donna Guy ${ }^{14}$ para el caso de Buenos Aires y lo corroboran nuestras fuentes.

En este sentido, la realidad de nuestro espacio de estudio no parece haber sido muy diferente a la de Bs. As. Por lo tanto, todo hace pensar que Emma y Clara Romeo, que fueron depositadas por su padre, Domingo Romeo, en el Asilo del Sagrado Corazón de Jesús de Azul, a cargo de la Asociación Damas de Caridad, el 22 de noviembre de 1899, fueron en realidad afortunadas, comparando su suerte con la de otras niñas. Un destino similar tuvieron las hermanas Bernardina y Natividad Barrionuevo, quienes fueron aceptadas por la presidenta del mismo Asilo, Marcelina B. de Dhers, aunque no así sus otros dos hermanos, también menores, Dionisio y Eduardo, porque, según lo explicaban en carta del 3 de enero al Defensor de Menores, el reglamento de la Institución era clara al respecto, al no permitir niños, sino sólo mujeres. Lo mismo podemos decir de Victoria y Antonia Cappa, de siete y tres años respectivamente, que en noviembre de 1901 fueron depositadas en el Asilo de Huérfanas del Sagrado Corazón de Jesús de Tandil, a cargo de las Damas de Caridad de esta ciudad, al ser sacadas del lado de la madre, tras comprobarse una denuncia que ponía de manifiesto que ésta ejercía la prostitución en la casa de tolerancia de Filomena Pelichotta. ${ }^{15}$ Claro que el paso por el Asilo también podía ser transitorio, hasta que alguna persona caritativa del pueblo formalizara ante el Defensor de Menores el pedido de la guarda legal de alguna menor. Así sucedió con Josefa Predondelli de Tandil, de doce años, que, tras el fallecimiento de la mujer que la había criado, estaba en el Asilo de las Damas de Caridad. En septiembre de 1903, la menor quedó bajo la guarda de la señora Concepción de Puentes. ${ }^{16}$ En otras oportunidades después de un tiempo, la madre reclamaba a la menor que estaba en el Asilo, como fue el caso de Mercedes Ibarra, quien en enero de 1905 fue reclamada por su madre, la misma que la había entregado antes. Aunque el lapso estipulado en el acta que al momento de su ingreso a la institución había firmado aun no había transcurrido, las Damas de Caridad consideraron que la niña había completado su educación y podía retornar con la madre. ${ }^{17}$ Finalmente, la mala conducta podía definir la salida de las niñas del Hogar, con destino a otro tipo de lugares en que se pensaba corregirán su mal proceder. Así, en diciembre de 1905, María Francisca Boulanger de Tandil fue sacada rumbo al Hogar Provincial en la Plata ${ }^{18}$ y en octubre de 1907, las Damas de Caridad informaban al Defensor de Menores de 
Tandil que, dada su mala conducta y de lo fallido de los intentos por corregirla, Juana Ortiz debía ser sacada del Asilo y trasladada al Asilo del Buen Pastor (probablemente el de Buenos Aires, al que Donna Guy se refiere como una cárcel y no como asilo de corrección, donde la represión y la corrección eran parte de un mismo dispositivo de control), por la misma razón. ${ }^{19}$

En las historias antes relatadas, encontramos ejemplos de la forma en que el control sobre determinados sectores de la población era ejercido, y de la colaboración que existía desde las instituciones de caridad hacia los poderes locales. Dicha colaboración era recíproca según las circunstancias ya que, si en el caso de Victoria y Antonia Cappa, fueron recibidas en el Asilo tras una denuncia comprobada que pesaba sobre la madre, de ejercicio de la prostitución, Juana Ortiz y María Francisca Boulanger, fueron sacadas del Asilo a partir de un pedido de las Damas de Caridad al considerar que la mala conducta de las chicas era peligrosa para el resto de sus compañeras. Frente a esta situación, el Juez de Menores de Tandil dio la autorización pedida por las señoras. En esto, vemos no sólo la ideología del control aplicada sobre ciertas personas, sino la de preservación de otros sectores de la misma sociedad a quienes ponían en peligro potencial aquellas acciones. A Victoria y Antonia Cappa había que protegerlas de la mala influencia de la madre, pero a su vez ellas estarían vigiladas en el Asilo en caso de manifestar conductas que hicieran presumir una “conducta desviada”. María Francisca y Juana se consideraban incorregibles, de manera que era necesario evitar que esa conducta “contagiara” al resto de las asiladas. La ideología del control se ligaba con la de contagio moral y social y la de apartar a quienes se consideraban peligrosos para preservar al resto del conjunto social. Nada más representativo de este clima de ideas que la carta que la presidenta de la "Sociedad Hermanas de los Pobres” de Tandil, ${ }^{20}$ envió al Defensor de Menores en agosto de 1888, informándole sobre la situación de los hijos menores de la mujer Gertrudis Palacios, a quienes la Sociedad le

... suministraba los alimentos, ropas i(sic) demás auxilios que demandaba su extrema pobreza; pero hace pocos días la referida mujer Gertrudis Palacios fugó de su casa abandonando dichos menores en poder de un hombre con quien mantenía relaciones ilícitas. Este no obstante disponer de los medios necesarios para la mantencion de estos pequeños por cuanto la Sociedad se los ha seguido suministrando hasta el presente, por causas que me son desconocidas, los ha entregado en poder de una persona extraña llamada Mercedes Villalba ... ${ }^{21}$ 
Sigue relatando que en poder de esta mujer los chicos están expuestos a innumerables peligros, y termina informando la dirección de la referida mujer y pidiendo al Juez que actúe de acuerdo a la ley para la protección de los menores. Evidentemente la situación de éstos es lo que predominaba a los ojos de esta institución de beneficencia y tal vez ante la sociedad. Lo condenable no era que Gertrudis Palacios mantuviera relaciones ilícitas con un hombre que no era el padre de sus hijos, sino que hubiera huido abandonándolos. Lo malo no era que éstos hubiesen quedado a cargo de este hombre, sino que éste a su vez los entregó a una extraña, quien parecía no darles la protección adecuada. Pocos días después, Alejandrina Dhers, secretaria de la Sociedad, comunicaba por medio de otra nota al Defensor que “... he llegado a saber que la mujer quien los tiene está por retirarse al campo así espero y ruego tenga la bondad de tomar medidas que crea necesarias lo mas pronto posible”. Ningún dato escapaba al control de las mujeres que tenían como misión proteger a los menores abandonados. ${ }^{22}$

\section{Los dispositivos del control: alcances y límites}

Hasta aquí hemos planteado algunos casos que ponen de manifiesto la forma en que los dispositivos de control eran aplicados sobre determinados individuos por las autoridades locales en colaboración con las instituciones de beneficencia y viceversa. Sin embargo, éstos, que podrían considerarse ejemplos “exitosos” del aparato moralizador, no constituían la regla, sino sólo una parte de la realidad. Si bien es cierto que los intentos de introducir pautas de moralización (tanto desde los sectores gubernamentales en todos los niveles, como desde las diferentes instituciones civiles) existieron, los resultados fueron variados. Tal como plantean Di Lisia y Bohoslavsky, no sólo debemos atender a la óptica de los discursos, sino las prácticas dentro de las instituciones, ya que “... Descubrir las intenciones y discursos de la elite no significa conocer todo el universo en torno a la cuestión del control social”. ${ }^{23}$

No siempre los menores eran depositados en los Asilos mencionados ya que, tal como en el caso de Buenos Aires, el problema de las vacantes era una realidad que demandaba un gran esfuerzo por parte de los Defensores de Menores quienes debían encontrar lugar en casas de familias para los que quedaban fuera de las instituciones locales. Esta tarea tomaba ribetes aún más complejos frente a las constantes situaciones de fugas del lado de sus guardadores que protagonizaban los menores, a lo que el Defensor debía dar parte a la policía para la captura, cual delincuente y, una vez hallado, 
devuelto a la familia o "colocado" con otra, según fuera el caso. Frecuentemente se escuchaban las razones que tenían los menores para haber escapado, y muchas veces se hacía lugar a su reclamo (aun en casos en los que sin fuga de por medio, declaraban no querer estar con la madre). Así sucedió con los menores Juana Ormazabal de 18 años y Antonio Ormazabal de 13, que eran reclamados por la madre, Josefa Ormazabal. Todos comparecieron ante el Juez de Menores de Tandil, además de don Domingo Algarañas, en cuya casa se encontraban y el vecino José Redondo. La madre manifestó querer tener a sus hijos a su lado, tras lo cual el Juez preguntó primero a Juana si ésa era su voluntad, manifestando no ser así, sino permanecer al lado de Domingo Algarañas, por los malos tratos y la mala vida que la madre les daba. Su hermano Antonio, a su vez, manifiestó querer estar con su hermana Juana y no con la madre. El Juez recabó en el mismo acto información de los otros presentes en relación a la conducta de Josefa, y ambos coincidieron en el ejemplo de inmoralidad y mala vida que ésta les daba a los pequeños que, según consta en otra nota, habían sido encontrados por estos hombres, vagando por el campo en compañía de la mujer. Por todo esto,

... La Defensoría en virtud de lo expuesto y demás antecedentes recogidos entre ellos la manifestación de otra de sus hijas llamada Maria la que también se resiste a seguir a la madre por darle ejemplos y consejos inmorales resuelve por el momento que los citados menores cigan (sic) depositados con Don Domingo Algarañas hasta tanto se adopte una resolución definitiva respecto a la tenencia permanente de los menores. ${ }^{24}$

En otros casos, eran los propios guardadores los que, tras la fuga, pedían que el menor que tenían a su cargo quedara nuevamente bajo responsabilidad del Defensor, para que éste arbitrase la solución que “estimase conveniente”. ${ }^{25}$ En mayo de 1899, se presentó a la Defensoría de Menores de Azul Doña Juana Robledo, denunciando la fuga de la menor Petrona Cardoso de 15 años, que se encontraba a su cargo desde hacía 10 años. Dijo saber que la chica estaba en casa del Sr. José M. Fernández y pidió a la Defensoría que la menor fuera colocada en otra casa. ${ }^{26}$ En el mismo mes, se presentó Juana Torras denunciando la fuga de la menor Elena Funes, que también le había sido entregada por la Defensoría de Azul el año anterior. En el mismo acto se presentó a comparecer la menor y expuso que la causa de su huida era a raíz del descontento que la señora de Torras manifestaba con relación a su trabajo. El esposo de la señora Torras aclaró que tal descontento obedecía a que ésta pensaba que la menor era autora de un hurto de un pendiente de oro y dinero y por esa razón decidieron hacer entrega de la menor a la Defensoría. ${ }^{27}$ Claro que no siempre el fin de la relación era traumático en el 
sentido que lo venimos describiendo, sino que a veces existían pedidos expresos de los guardadores de traspasar sus derechos sobre el chico o chica a su cargo a favor de otra persona de su confianza, frente a lo que consideraban su imposibilidad de seguir cumpliendo con las obligaciones tomadas al respecto. Tal era así que, en Enero de 1893, se presentó ante el Defensor de Menores de Tandil el vecino José Tizado, y expuso que "no siéndole posible continuar con el deber que se impuso al hacerse cargo de la menor Antonia Gainza ... viene a solicitar de esta Defensoría se le permita depositarla en casa de dicho Señor Suárez Martínez, persona de reconocida moralidad y honradez”. Estando este vecino presente y de acuerdo, la Defensoría resolvió hacer lugar al pedido de Tizado. ${ }^{28}$ Los contratiempos económicos eran frecuentemente aludidos como causa para no poder cumplir con esas obligaciones, situación que afligía no sólo a los guardadores legales sino también a los propios progenitores, como lo atestigua el caso del matrimonio formado por Don Carlos Bellami y Doña Nieves Pérez, quienes declararon ante el Juez que “ceden (sic) y donan espontáneamente al referido Don Antonio Bellami, tío carnal de aquél a su legítimo hijo, llamado también Carlos de veinte y un mes de edad para que se encargue de su tutela ...” ${ }^{29}$ Aristas más graves parecen revelarse cuando se trataba de mujeres solteras o que no contaban con la asistencia del esposo por razones circunstanciales, como el caso de María de Iturralde, casada y francesa de nacionalidad que en octubre de 1893 concurrió a la Defensoría a exponer su situación. Estando su esposo en Europa y teniendo ella que salir a trabajar como empleada doméstica para ganarse el sustento, no podía hacerse cargo de su hijo menor de dos años. Por eso pedía a la Defensoría que se hiciera cargo del mismo su hijo político, Juan Iturralde, casado y con los medios suficientes para atender al menor, al que cede, dice, todos los derechos que sobre el niño tiene como madre. ${ }^{30}$ Menos sabemos de lo que le sucedió a la menor Irene Ferreira, quien huyó de casa de su guardadora, Doña Máxima J. de Fernández en abril de 1899. Sólo conocemos la fecha de su rápida captura: el día siguiente a la denuncia, el 18 de abril. ${ }^{31}$ Similar situación se dio con Amancio Aguilar de Olavarría, menor argentino de diez años, que fugó en agosto de 1895 del hogar de José Ojeda donde estaba depositado por el Juez de Menores de ese pueblo. Los ejemplos pueden multiplicarse. ${ }^{32}$

El universo de familias o simplemente personas que se hacían cargo de menores era más que complejo. Así lo vimos para casos de Olavarría y Azul y podemos corroborarlo en Tandil. ${ }^{33}$ Claro que en algunas ocasiones no se trataba sólo de mujeres solteras o matrimonios conocidos por familiares del menor desamparado, sino de 
señoritas o matrimonios pertenecientes a la elite local, como el caso de Ramón Gamez en Olavarría vinculado a la explotación canteril y a la política local, o de Pía Lizarralde, Ramón Gómez, Ramón Vázquez Brac, Camilo Ortiz o Dolores López Osornio, en Tandil. Todos ellos, de cierto nivel económico, ligados algunos a la tierra o al comercio y ocupaban un lugar de prestigio en la reducida sociedad local. ${ }^{34}$ Observamos también que las mismas personas solicitaban la guarda de algún chico al Juez de Menores en reiteradas oportunidades. En junio de 1873, Doña Concepción Giménez, a la que antes nos referimos se había hecho cargo de la menor Feliciana Guayama. En octubre de 1880, la misma señora tomó a su cargo a la menor Irene Arancibia, de común acuerdo con el padre de la niña. ${ }^{35}$ También Camilo Ortiz y su esposa manifestaron una actitud similar, tomando a su cargo la crianza de la menor Felipa Rodríguez en diciembre de 1879, y de Natividad Miranda en marzo de $1881 .{ }^{36}$ Cabe preguntarse si estamos frente a una sincera actitud filantrópica o si se trataba de la contratación de mano de obra doméstica. Si bien no sabemos nada sobre el destino de estas menores entre estas familias que las recogieron, todo hace pensar que estas personas tomaban a su cargo menores (especialmente niñas), porque necesitaban gente que trabajara a su servicio y tal como los contratos lo manifiestan, darles casa, comida, vestido y educación era el pago considerado justo, a mitad de camino entre la caridad y la reciprocidad. En cuanto a la vida que llevaron en las casas de familias a las que ingresaban, algo podemos inferir en términos más generales sobre otros casos de los que tenemos alguna noticia.

Tal como planteaba Donna Guy para el caso de Buenos Aires, las niñas que eran enviadas a la cárcel de esa ciudad habían en algún caso cometido un hurto o ejercido la prostitución pero la mayoría sólo eran pobres, pertenecientes a los sectores populares y se los destinaba a las tareas más serviles. Cuando salían de la cárcel las mujeres o de la penitenciaría las varones, se los colocaba en algún hogar “... en el que ingresaban como trabajadores, no como niños bajo custodia ....”37 De las fuentes antes aludidas esto se desprende claramente. Si en el caso de la menor Funes se deja entrever un descontento con ella por un presunto robo del que nada sabemos, la situación de precariedad en la que los menores eran aceptados por las familias que se hacían cargo queda más claro en el caso de María Gutiérrez de Olavarría. El dieciséis de septiembre de 1894, se presentó al Juzgado de Paz de ese pueblo el doctor en medicina Olivieri, de 38 años, casado, de origen italiano y con siete años de residencia en el país a denunciar la fuga de la menor citada, quien se encontraba en su casa por orden del Juzgado de Paz. El médico acusó a la menor de haberse llevado un anillo de oro con un brillante. El tres del mes siguiente 
compareció María, quien dice ser doméstica, no saber leer ni escribir y además declaró haber fugado a causa de la "mala vida" que le daba la esposa del doctor. La chica niega haberse llevado nada más que ropa de su propiedad y dice haber ido directo a lo del señor Lorenzo Gamez (a la sazón Defensor de Menores), y allí había permanecido hasta el momento en que la aprehendieron. ${ }^{38}$ Más explícito queda en el caso de la menor Florentina Saavedra de Tandil, quien en marzo de 1900 fue pedida por el señor José Carré, quien se presentó en la Defensoría “... solicitando una menor para el cuidado de su señora madre, y existiendo en depósito la menor Florentina Saavedra, le fue concedida bajo las siguientes condiciones ...”, siendo éstas los términos habituales del contrato antes mencionado. ${ }^{39}$ Aquí vemos cómo en la práctica los menores eran simples trabajadores depositados en casa de familia. Se suponía que para educarlos, pero el caso de María muestra abiertamente que no era así, ya que ni siquiera sabe firmar. Los malos tratos son la causa aludida con más frecuencia en las declaraciones de los fugados para justificar su decisión de huir, ${ }^{40}$ y el supuesto robo la que usan los guardadores para descalificar a la víctima. Esos malos tratos se reflejan también en el informe que el Defensor de Tandil elevó al Defensor General ante un pedido de éste sobre la situación de la menor Micaela Carabajal, quien debió ser sacada por la autoridad de manos de doña Francisca Oliver dado el "estado lamentable” en que se encontraba. De acuerdo a la información que el Defensor había recabado, “... Por mucho tiempo fue la única criada de la casa ocupándola en todo genero de trabajos, incluyendo los que no corresponden a su sexo. ...” Sumado a esto, el ejemplo de moralidad que había recibido no era de los mejores y no se había atendido a su educación. Razones que la autoridad de Tandil encontraba suficientes para depositarla en guarda en casa de la familia del “honrado vecino Norberto Melo”. ${ }^{41}$

Pero había un problema mayor al del maltrato físico o la "mala vida” que podía incluir, según se desprende de las declaraciones de los menores, el estar mal vestidos, no acceder a la educación, trabajar más de lo recomendado para su edad o hasta no comer bien. Las niñas corrían un riesgo mayor: el de la posible "seducción” o violación por parte de sus guardadores. Esto es lo que le sucedió a María García de Olavarría. El 18 de agosto de 1896 se presentó Teodoro Jansen a denunciar la fuga de dicha menor, quien en realidad estaba depositada en casa del Juez de Menores. En la misma fecha compareció la chica de dieciséis años, diciendo que 
... el día de su santo el quince del corriente, siendo las 7 p. m., en circunstancias la declarante estaba lavando los platos, su guardador le dio cita para que se ocultara en el excusado con el fin de tener contacto sensual, lo que la declarante se rehusó, habiéndolo intentado por dos veces ...

A ella también la acusaron de robar un anillo, cosa que negó rotundamente, y por carecer de pruebas en su contra, resultó sobreseída. En una declaración posterior, ella negó haber tenido algún tipo de contacto con su guardador de manera forzada o voluntaria. ${ }^{42}$ Qué la llevó a cambiar de opinión no lo sabemos. Si era lo primero mentira o siendo verdad se desdijo para no quedar tan expuesta, son sólo conjeturas. Lo cierto es que la "mala vida” podría muy bien incluir este tipo de afrentas pero las muchachas se abstenían de declararlo, por la dificultad de probarlo y probablemente para no exponer su honra públicamente. ${ }^{43}$

En otros casos, el deseo de fugar de la mala vida, llevaba a muchos hijos a dejar el hogar paterno o materno, como Carmelo Aguirre Zavala, oriental, de 15 años. El diecisiete de mayo de 1896 se presentó ante la Comisaría de Olavarria Doña Ceferina de Aguirre Zavala, de 37 años, casada dando cuenta de la huida del citado menor, su “entenado”. El tres del mes siguiente se presentó para dar cuenta de que el chico había "vuelto al seno del hogar", por lo que pedía a la policía que dejara sin efecto su denuncia anterior. ${ }^{44}$ Más grave era tal vez la situación de la menor Rafaela Martínez, que huyó de su casa y se refugió en lo de su abuela, Ruperta Moraga. Según declaró la madre de la menor, Doña Trinidad Torres, en marzo de 1892 ante el Juzgado de Menores de Olavarría, su hija se negaba a vivir con ella por causas que ignoraba y pidió la intervención de la Defensoría para que la chica desistiera de su decisión. Por razones que desconocemos el Juez decidió depositarla en casa del vecino, José María Almada, por considerar que no era conveniente que la menor viviera con su madre. ${ }^{45}$ En otros casos, son los mismos menores los que buscaban el amparo de las autoridades para resolver sus problemas cotidianos y familiares. Tal es el caso de la menor Máxima Aguirre, quien en enero de 1896 compareció ante el Defensor de Menores de Azul y expuso que “... en virtud del mal trato que le da su hermano Nicasio, mayor de edad, le es imposible continuar al lado de su mamá Juana de Aguirre. Que hasta ha llegado momento en que su hermano la ha amenazado con darle un tiro, lo cual teme efectúe cualquier día”. Por esto pedía al Defensor que la depositara en la casa de su hermana Cleta. El Juez resolvió hacer lugar al reclamo de la menor y dejarla en casa de su hermana, por haber comprobado que las denuncias y peligros que corría Máxima en casa de su madre eran ciertos. ${ }^{46}$ Pero el caso siguió su curso y tomó intervención el 
Defensor General de La Plata, quien en octubre del mismo año envió una carta con indicaciones a su par de Azul, diciendo que debía resolver la situación de la menor Máxima Aguirre y su hermana Amelia, de acuerdo a la conducta moral de la madre. En principio debía averiguar si la madre Juana de Aguirre tenía la tutela legal de las menores, y de ser así y si lo creyere conveniente debía buscar quien la reemplazara en esa tutela, porque aparentemente ésta no cumplía “... con las obligaciones que la naturaleza y las leyes le imponen ...”, no sólo las de madre y tutora sino que se creía necesario también que observara una buena conducta “... como mujer viviendo honestamente y sin que nadie tenga que decir de ella”. ${ }^{47}$ Josefa Ríos, por su parte, se negaba a regresar con su madre, y prefería permanecer en Bahía Blanca donde vivía una hermana suya y su cuñado. La negativa es por causa, dice, de estar su madre siempre ebria y tratarla muy mal. ${ }^{48}$

De lo expuesto se desprende la complejidad de la realidad a la que nos estamos refiriendo, máxime teniendo en cuenta que estamos frente a un espacio que, aunque recepcionaba los intentos de control y los discursos moralizadores que se producían en Buenos Aires, al ser llevados a la práctica, los resultados no siempre fueron tan positivos. Es dable además tener muy en cuenta que esos controles se aplicaban sobre individuos que desarrollaban una serie de estrategias para, si no resistirlos, al menos usarlos a su favor, utilizando los intersticios del sistema.

\section{Conclusiones}

En el contexto de modernización al que asistió Argentina a fines del siglo XIX se acentuó el sentimiento de desorden social. El discurso de la maternidad fue una herramienta útil como medio de control, al intentar reafirmar a las mujeres en su lugar tradicional como madres en el seno del hogar, pero dotándolas de la responsabilidad de formar a los futuros ciudadanos del Estado en proceso de consolidación.

Entre los sectores considerados peligrosos para el orden social y necesarios de ser controlados estaban los sectores populares y, en particular, las mujeres y los niños. Como evidencian las fuentes a las que nos hemos referido, las formas familiares que llevaron a la práctica estos actores distaban mucho del ideal que se pretendía imponer. La beneficencia adquirió en este contexto un nuevo desarrollo y sentido: si por un lado era un medio para canalizar las demandas que provenían desde una sociedad cada vez mas convulsionada, fue un espacio también donde se resignificó el lugar de las mujeres 
(en particular las de los sectores notables), en la sociedad. Estas encontraron allí un lugar para la participación en el espacio público, siendo al mismo tiempo destinatarias de los discursos de la maternidad y el control que se pretendía instalar sobre todas las mujeres, y artífices de introducir entre los sectores populares pautas de moralización por medio de su participación en las instituciones filantrópicas.

De las situaciones expuestas se desprenden realidades familiares donde las madres solas, los entenados, los menores colocados en casa de familias donde se les da mala vida, etc. muestran una realidad bastante diferente de la de la familia como espacio de orden y sosiego, y dan por tierra con la imagen de la madre cariñosa y abnegada, con el instinto natural de la madre, y el amor filial. Situación más compleja aun si tenemos en cuenta que estamos analizando pueblos de la frontera bonaerense, donde la laxitud de las normas parece haber sido una constante. ${ }^{49}$ En fin, una cotidianeidad más compleja donde la insistencia del discurso adquiere sentido: no reflejaba una realidad existente sino ideal, que buscaba imponerse. Y fue en este contexto en el que la función del Defensor de Menores y de las asociaciones de beneficencia adquirieron un sentido más claro: eran los encargados de corregir las desviaciones que estos sectores de la sociedad ponían de manifiesto. Cabe tener en cuenta lo planteado por Di Lisia y Bohoslavsky acerca de la efectividad del control. Si bien no podemos desestimar los enormes esfuerzos que desde los sectores dominantes, intelectuales, de gobierno, institucionales, profesionales, etc. se desarrollaron en aras de controlar a los sectores de la sociedad que podían poner en peligro el modelo, es cierto que el control efectivamente logrado adquiere otro sentido cuando lo miramos desde las instituciones encargadas de llevarlo a la práctica o desde la realidad de los sujetos sociales. Como vimos a partir de las historias brevemente relatadas, la vida de las personas se vio menos influida aún por tales dispositivos. Si, en algunos casos el control fue efectivo, parece ser que los esfuerzos eran siempre insuficientes para atender a una realidad cada vez más diversa.

\section{REFERÊNCIAS BIBLIOGRÁFICAS:}

BJERG, Maria. El mundo de Dorotea. La vida en un pueblo de la frontera de Buenos Aires en el siglo XIX. Buenos. Airess. Imago Mundi, 2004.

BONAUDO, Marta. Cuando las tuteladas tutelan y participan. La Sociedad Damas de Caridad (1869-1894), en prensa. 
CARREÑO, Karina. Cuestiones... delicadas y escabrosas. La legalización de la prostitución en Tandil. (1870-1910). 2005. Tesis de Licenciatura, UNCPBA, Tandil.

DALlA CORTE, Gabriela y PIACENZA, Paola. A las Puertas del Hogar. Madres, niños y Damas de Caridad en el Hogar del Huérfano de Rosario (1870-1920). Rosario: Prohistoria Ediciones, 2006.

DE PAZ TRUEBA, Yolanda. Mujeres: del espacio doméstico a la esfera pública. El largo camino hacia la inclusión. 2005. Tesis de Licenciatura, UNCPBA, Tandil.

Beneficencia, control social y disputas de las mujeres en el espacio público del sur bonaerense a fines del siglo XIX y principios del XX. En: Revista Temas de Historia Argentina y Americana n. 9, julio-diciembre de 2006, Facultad de Filosofía y Letras, Universidad Católica de Buenos Aires.

DI LISIA, M. S. y BOHOSLAVSKY, E. (eds.). Instituciones y formas de control social en América Latina 1840-1940. Una revisión, Buenos Aires.. Prometeo, 2005.

DONZELOT, Jacques. La policía de las Familias. España: Ed. Pre textos, 1990.

GONZALEZ, Favio. Niñez y beneficencia: un acercamiento a los discursos y las estrategias disciplinarias en torno a los niños abandonados en Bs. As. de principios del silgo XX (1900-1930). En: MORENO, José Luis (comp.). La política social antes de la política social (Caridad, beneficencia y política en Buenos Aires.., siglos XVII a XIX). Trama editorial, Buenos Aires., Prometeo Libros, 2000.

GUY, Donna. Niñas en la cárcel. La Casa Correccional de mujeres como instituto de socorro infantil. En: GIL LOZANO, F., PITA, V. S. y INI, M. G. (Dirs.). Historia de las mujeres en la Argentina, Siglo XX, Buenos Aires.. Taurus, 2000. t. II.

MATEO, José. Bastardos y concubinas. La ilegitimidad conyugal y filial en la frontera pampeana bonaerense (Lobos, 1810-1869). En: Boletín del Instituto Ravignani n. 13, 1996.

MORENO, José Luis. La casa de niños Expósitos de Bs. As. Conflictos institucionales, condiciones de vida y moralidad de los infantes 1779-1823. En: MORENO, José Luis (comp.). La política social antes de la política social. (Caridad, beneficencia y política en Bs. As., siglos XVII a XIX). Trama editorial, Buenos Aires., Prometeo Libros, 2000.

NARI, Marcela. Políticas de maternidad y maternalismo político. Buenos Aires.. Biblos, 2004.

RÍOS, J. C. y TALAK, A. M. La niñez en los espacios urbanos. En: DEVOTO, F. y MADERO, M. (dirs.). Historia de la Vida Privada en la Argentina. Buenos Aires.. Taurus, 2000. t. 2. 
ROUDINESCO, Elisabeth. La familia en desorden, F.C.E., Buenos Aires.. 2003.

SEDEILLAN, Gisela y DE PAZ TRUEBA, Yolanda. Las mujeres antes los estrados de la justicia. Agresiones sexuales en la campaña centro sur bonaerense a fines del siglo XIX. En: Actas de las IV Jornadas Nacionales Espacio, Memoria e Identidad, Rosario, Pcia. De Sta. Fe, 4, 5 y 6 de octubre de 2006.

SURIANO, Juan (comp.). La cuestión social en Argentina, 1870-1943. Buenos Aires.. La Colmena, 2000.

VASALLO, Jacqueline. Mujeres delincuentes. Una mirada de género en la Córdoba del siglo XVIII. Córdoba: Centro de Estudios Avanzados, Universidad Nacional de Córdoba, 2005.

VIVALDA, Graciela. Solas, huérfanas y extranjeras. Un destino incierto para las niñas abandonadas en Rosario a finales del siglo XIX. En: $X^{o}$ Jornadas Interescuelas, Rosario, 2005.

ZIMMERMANN, Eduardo. Los Liberales reformistas. La cuestión social en la Argentina, 1890-1916. Buenos Aires.. Sudamericana, 1995.

Paz Trueba, Yolanda de. Charity Exercise as prestige space and social control tool, in the centre and south of Buenos Aires province at the end of nineteenth century. História, São Paulo, v. 26, n. 2, p. 366-384, 2007.

Abstract: In Argentine of the end of nineteenth century, it was very important for the State (that has been feeling threaten by social disorder) to consolidate itself by installing a society and a family model. This article intends to analyse not only how charity institutions could moralize agents in some towns of centre and south of Buenos Aires province, but also the limits that the imposed controls have found in practice.In those institutions, upper class women were control transmitters over popular sectors, at the same time they found a way to exercise citizenship, although they had civil rights only like mothers.

Keywords: Charity, Women, Citizenship

Artigo recebido em 09/2007. Aprovado em 12/2007.

\section{NOTAS:}

\footnotetext{
* El presente artículo forma parte de la investigación realizada en el marco de mi proyecto de tesis doctoral inscripto en el Doctorado de Historia de la Universidad Nacional del Centro, dirigido por la Dra. Lucía Lionetti y financiado por una Beca de Posgrado otorgada por CONICET en febrero de 2005.
} 
** (IEHS) Instituto de Estudios Histórico Sociales, Facultad de Ciencias Humanas, Universidad Nacional del Centro de la Provincia. de Buenoss. Aires., (7000) Tandil, Provincia de Buenos. As. - CONICET (Consejo Nacional de Investigaciones Científico Técnicas, Argentina).

${ }^{1}$ La cuestión social ha sido trabajada por múltiples autores entre los que podemos mencionar a Suriano, 2000. También Zimmermann, 1995, entre otros.

${ }^{2}$ Nari, 2004, p. 18.

3 El conventillo, la promiscuidad de la convivencia y el hacinamiento en el caso de grandes conglomerados urbanos como Buenos Aires y Rosario, y la ilegitimidad de los nacimientos, el concubinato y todo tipo de relaciones "ilícitas" en amplios sectores del territorio donde confluían nativos e inmigrantes, abonaban estas preocupaciones. Sin embargo, debemos tener en cuenta que no sólo entre las clases populares las relaciones ilícitas y los nacimientos ilegítimos eran una constante. También se dieron entre las familias de sectores más acomodados, entre los que “mantener la discreción” era la regla, dado el peso de la condena social que debían soportar. De hecho el torno de la Sociedad de Beneficencia da cuenta de la necesidad de atender a esta realidad: muchos de los niños que allí eran depositados, eran hijos de señoritas de la sociedad porteña que por medio del abandono ocultaban la deshonra familiar.

${ }^{4}$ Nari, 2004, p. 62. Cabe tener en cuenta lo planteado por Elisabeth Roudinesco para el caso europeo, quien afirma que tal idea de desorden social no es un producto del siglo XIX, sino por el contrario, se remonta a épocas lejanas, a raíz de las transformaciones que la familia ha ido experimentando a lo largo de los siglos. Así, se habría dado en el siglo XVIII un cambio que tuvo repercusiones en el XIX y en el que se habrían visto modificados los roles que cada miembro tenía al interior de la misma. En principio se trataría de la revalorización del papel de la madre y el fortalecimiento del vínculo con los hijos, lo cual fue un medio para reafirmar el papel tradicional de la mujer en el hogar, en el marco de la Revolución Francesa, momento en el que las mujeres hicieron una aparición significativa en el espacio público. La salida de las mujeres del hogar se sentía como una amenaza que según esta autora se conjuró reforzando el papel tradicional de la mujer en el hogar. En segundo término, se modificó la figura del padre y su autoridad, que dejó de ser de inspiración divina, para transformarse en el pater familias. Tenía poder sobre los demás miembros de la casa pero debía usarlo éticamente, porque en última instancia era el Estado quien detentaba ese poder y podía quitárselo. Aunque según Roudinesco, estas transformaciones generaron entre los contemporáneos la sensación de crisis familiar, y particularmente del predominio patriarcal, éste, dice, no se vio disminuido, sino más bien transformado (Roudinesco, 2003).

${ }^{5}$ Bonaudo, en prensa.

${ }^{6}$ Especialmente a los niños futuros ciudadanos y trabajadores, y las mujeres, futuras madres.

${ }^{7}$ La presencia de la niñez abandonada era una constante en Bs. As. desde la época colonial tal como lo señala José Luis Moreno, quien plantea que la creación en 1779 de la Casa de Niños Expósitos, tuvo el objetivo de dar un principio de solución a la gran cantidad de niños abandonados en la vía pública, además de los huérfanos. A fines del siglo XIX, en el contexto del crecimiento económico y la inmigración masiva, la preocupación por ellos adquirió nuevas dimensiones, al vincularlos con un sentido de peligrosidad social y moral. En el marco discursivo liderado por la elite que presentaba a los niños como el futuro de la nación, el abandono de éstos y su presencia en las calles eran una preocupación central en tanto se creía que esos niños podían devenir en los delincuentes del futuro o, peor aun, en agitadores sociales (MORENO en MORENO, 2000).

8 Rivadavia pretendió darle a su administración un marco secularizador e iluminista. Creía en la importancia de las funciones femeninas en las tareas caritativas y en la necesidad de una cierta presencia del Estado (Moreno, 2000).

9 Tal como plantea Donzelot para el caso europeo, la preocupación en el Siglo XVIII por la niñez abandonada tuvo su contraparte en dos principios de solución. Por un lado con la figura del médico en las familias burguesas (sea a través de la redacción de los manuales de crianza con consejos dirigidos a las madres o con su presencia física). Pero en el caso de los sectores populares, quienes no tenían el acceso al médico ni a la lectura, la introducción de controles y de pautas de moralización y saneamiento de su vida diaria, se dio a través de instituciones mutuales, civiles y filantrópicas de todo tipo que vinieron a reemplazar a los sistemas de hospitales y asilos estatales colapsados y obsoletos (Donzelot, 1990).

10 De acuerdo con el análisis que Graciela Vivalda realizó para la ciudad de Rosario (con quien encontramos muchas similitudes para nuestro caso de estudio), los defensores eran iletrados, y llevaban un control de la educación de los menores, así como listas de colocación de estos en casas de familias particulares (Vivalda, 2005).

${ }^{11}$ Guy en Lozano, Pita, y Ini, 2000, t. II. Tanto Guy como Vivalda, a la que antes nos referimos, coinciden en señalar que la colocación en casas particulares respetables terminaba siendo una forma de proveer de sirvientes a tales familias. Dice Vivalda que las defensorías de menores paulatinamente se transformaron en agencias de colocación de sirvientes menores de edad. Con relación a este tema, es 
interesante el estudio de Jaqueline Vasallo, quien para otro tiempo y espacio encuentra que la colocación en casas "honestas" era una forma de castigar con una reclusión de hecho a mujeres (menores o no), que habían cometido algún delito. A falta de un lugar para que cumplieran su condena, o porque revestían cualidades especiales como su condición social o el estar embarazadas, la guarda en casas de familia era una forma más de encierro, de control social. (Ver Vasallo, 2005).

${ }^{12}$ Gonzalez en Moreno, 2000. p. 173.

${ }^{13}$ Ríos \& Talak en Devoto \& Madero, 2000, t. 2.

${ }^{14}$ Guy, 2000.

${ }^{15}$ Archivo Histórico Municipal de Tandil (AHMT): Defensoría de Menores, Actas, Libro 1067 (18731918), folio 171. Sobre el tema de la prostitución en Tandil y de Filomena Pelichotta en particular, ver Carreño, 2005.

${ }^{16}$ AHMT: Defensoría de Menores, Actas, Libro 1067, Op. cit., folio 183.

17 AHMT: Defensoría de Menores, Correspondencia, Libro 1066. Frecuentemente la soledad o la desprotección económica llevaba a mujeres solteras o abandonadas a entregar a sus hijos y si su situación mejoraba, regresaban por ellos. Para este tema ver Dalla Corte \& Piacenza, 2006.

18 AHMT: Defensoría de Menores, Correspondencia, Libro 1066, Op. cit. Con relación al caso de M. Francisca Boulanger nos hemos referido en DE PAZ TRUEBA,. 2005. la acción benéfica en Tandil desde la década de 1880. Las Hermanas de los Pobres dependían de la Logia Masónica local y tenían a su cargo el Asilo San Juan, primer hospital del pueblo, pero se ocupaban de los pobres en forma personalizada, tal como se desprende de la nota referida. Estos temas han sido trabajados en De Paz Trueba, 2005; 2006.

${ }^{19}$ AHMT: Defensoría de Menores, Correspondencia, Libro 1250, 1905-1920.

${ }^{20}$ Esta institución y las Damas de Caridad monopolizaban la acción benéfica en Tandil desde la década de 1880. Las Hermanas de los Pobres dependían de la Logia Masónica local y tenían a su cargo el Asilo San Juan, primer hospital del pueblo, pero se ocupaban de los pobres en forma personalizada, tal como se desprende de la nota referida. Estos temas han sido trabajados en DE PAZ TRUEBA, Yolanda, Mujeres: del espacio doméstico a la esfera pública. El largo camino hacia la inclusión, Tesis de Licenciatura, Op. Cit. ; "Beneficencia, prensa y educación: tres caminos hacia la inclusión de la mujer en la esfera pública. Tandil, fines del siglo XIX y principios del XX” en Revista Avances del CESOR, (Centro de Estudios Regionales), Facultad de Humanidades y Artes de la Universidad Nacional de Rosario, Pcia. de Santa Fe, Argentina, 2005; "Beneficencia, control social y disputas de las mujeres en el espacio público del sur bonaerense a fines del siglo XIX y principios del XX”, en Revista Temas de Historia Argentina y Americana $\mathrm{N}^{\mathrm{0}}$ 9, julio-diciembre de 2006, Facultad de Filosofía y Letras, Universidad Católica de Bs. As.

${ }^{21}$ AHMT: Defensoría de Menores, Correspondencia, Libro 1066, Op. Cit.

${ }^{22}$ AHMT: Defensoría de Menores, Correspondencia, Libro 1066, Op. cit.

${ }^{23}$ Di Lisia \& Bohoslavsky, 2005. p. 11.

${ }^{24}$ AHMT: Defensoría de Menores, Correspondencia, Libro 1066, Op. cit.

${ }^{25}$ La urgencia por la denuncia y la rápida respuesta y actuación del Juez de Menores en el caso de tan sólo una sospecha sobre la conducta de los menores en guarda, adquiere otras dimensiones al analizar los términos del contrato que se firmaba entre las personas que se hacían cargo de algún chico o chica y la autoridad competente e incluso a veces entre los padres que cedían a sus hijos, ya que no siempre se trataba de menores huérfanos. Dicho contrato especificaba (al menos para el caso de Tandil a los que hemos tenido acceso), además de la obligación de alimentar, vestir, educar y formar al menor en los preceptos de la religión católica, que “... de cualquier falta ... deberá darse cuenta inmediata al Defensor de Menores para obrar según su merito o que corresponda ...” Tal obligación competía tanto a quien tomaba a su cargo al menor como a éste. AHMT: Defensoría de Menores, Actas, Libro 1067, Op. cit., folio 2, 3, 5, entre otros.

${ }^{26}$ Archivo Municipal de Azul (AMA): 1899, Robledo Juana por la menor Cardoso, Petrona.

${ }^{27}$ AMA: 1899, Torras Juan P. por la menor Elena Funes.

${ }^{28}$ AHMT: Defensoría de Menores, Actas, Libro 1067, Op. cit., folio 101.

${ }^{29}$ AHMT: Defensoría de Menores, Actas, Libro 1067, Op. cit, folio 5. También ver folio 102, Febrero de 1893, Carlos Maidana cede la tenencia de su hijo Gregorio de trece años; folio 114, en septiembre de 1896, Eusebia Vázquez, soltera de 19 años domiciliada en Estación Vela, cede a su hijo de tres meses a doña Emilia Haedo, casada y también de Vela; similares en folios 115, 185 y 222 entre otros.

${ }^{30}$ AHMT: Defensoría de Menores, Actas, Libro 1067, Op. cit, folio 103. También Tomasa Díaz hace entrega en octubre de 1893, de su hijo de un año, Fortunato Díaz, al que no puede criar por dedicarse al servicio doméstico. Ibidem, folio 104.

31 AMA: 1899, Máxima J. de Fernández por la menor Irene Ferreira. 
32 Archivo Histórico Municipal de Olavarria (AHMO): 1895, Ojeda José da cuenta de la fuga del menor Amancio Aguilar. Ver también: 1895, Recalde Juan da cuenta de la fuga del menor Pedro Lorray; 1895, Montenegro Dolores T. da cuenta de la fuga de la menor Dominga Lara, entre otros.

33 A modo de ejemplo podemos mencionar el caso de doña Concepción Giménez, mayor de edad y soltera, quien en junio de 1873 se hizo cargo ante el Defensor firmando el contrato correspondiente, de la menor Feliciana Guayama de once años, huérfana de padre y madre. AHMT: Defensoría de Menores, Actas, Libro 1067, folio 2.

${ }^{34}$ AHMT: Defensoría de Menores, Actas, Libro 1067, Op. cit , folios 39, 49, 50, 70, entre otros.

${ }^{35}$ AHMT: Defensoría de Menores, Actas, Libro 1067, Op. cit , folios 2 Op. cit. y 52.

${ }^{36}$ AHMT: Defensoría de Menores, Actas, Libro 1067, Op. cit folios 39 y 46.

${ }^{37}$ GUY, Donna: "Niñas en la cárcel, Op. cit. p. 28.

${ }^{38}$ AHMO: 1894, Gutiérrez María, Fugada.

${ }^{39}$ AHMT: Defensoría de Menores, Actas, Libro 1067, Op. cit, folio 142.

${ }^{40}$ Así lo manifestó por ejemplo Salvador Gil Ledesma al Comisario de Tandil, tras fugar de la casa de Federico Demarchi, donde se encontraba depositado. AHMT: Defensoría de Menores, Correspondencia, Libro 1066, Op. cit.

${ }^{41}$ AHMT: Defensoría de Menores, Actas, Libro 1067, Op. cit, folio 10.

${ }^{42}$ AHMO: 1896, Jansen Teodoro, damnificado. Dando cuenta de la menor fugada García María (presa) y sospecha de hurto.

${ }^{43}$ En otro trabajo hemos analizado la cuestión de las violaciones en el mismo marco espacio temporal y la incidencia de la cuestión de la honra y las relaciones cara a cara en estos espacios de frontera. Ver Sedeillan \& De Paz Trueba en Actas, 2006.

${ }^{44}$ AHMO: 1896, Aguirre Zavala Carmelo, su fuga del hogar paterno.

${ }^{45}$ AHMO: Correspondencia, 29-3-1892.

46 AMA: 1896, Máxima Aguirre (menor) pide ser sacada del lado de la madre. Antes nos referimos al caso de los menores Juana y Antonio Ormazabal, quienes se negaban a volver al lado de la madre, reclamo que también fue escuchado por el Juez del caso.

${ }^{47}$ AMA: 1896, Defensoría de Menores. Notas varias.

${ }^{48}$ AMA: 1894, Notas varias de la Defensoría de Menores.

49 Como plantea José Mateo, la frontera con las altas tasas de movilidad espacial habría favorecido la ilegitimidad en los nacimientos, producto de relaciones ilícitas de amplio tipo, a gran distancia de las normas sobre el ideal de familia que los discursos planteaban y que se pretendía imponer desde algunas instituciones (Mateo, 1996). También sobre la flexibilidad de los patrones conyugales y sexuales ver Bjerg, 2004. 